\title{
Staffing After Mergers And Acquisitions: A Human Resource Management Case Study
}

Arthur K. Fischer, Pittsburg State University, USA

Tom Rush, Pittsburg State University, USA

\begin{abstract}
An HRM case dealing with problems encountered as a company seeks to integrate employees following an acquisition. Discussion concerns how the case is used to exhibit staffing issues of $M \& A s$.
\end{abstract}

Keywords: HRM case; Mergers \& acquisitions

\section{INTRODUCTION}

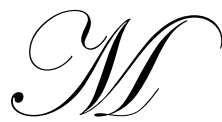

idwest Education, Inc. is a major supplier of educational materials for the United States. The company focus is on learning tools and systems for use in technology, science and business classrooms. In addition, it develops and provides books, manuals, videos, software and hardware used in the fields of technology education, instructional development and business applications.

The company has its headquarters and primary manufacturing plant in a major Midwest community. In addition, the Creative Development offices are located in Massachusetts and California. Transportation, Service and Maintenance facilities are headquartered out of Texas, with major branches in Baltimore and Phoenix.

The three main divisions exemplify three different strategies: cost-reduction, quality enhancement, and innovation (as discussed by Schuler and Jackson, 1987).

Transportation, Service and Maintenance. The primary strategy of the Transportation, Service and Maintenance Division is cost-reduction. Midwest Education, Inc. has long been known for providing service and maintenance programs which are very reasonably priced.

Manufacturing. The primary strategy of the Manufacturing Division is quality enhancement. Midwest education, Inc. has an enviable history of providing the highest quality products which have been adopted by first-rate schools and corporate training programs.

Creative Development. The primary strategy of the Creative Development Division is innovation. Midwest Education, Inc. is widely known for providing truly cutting edge teaching materials which always mirror the latest techniques and processes.

Various HRM problems occur at these different facilities. These problems require students to develop responses and show how their responses can support the overall strategic plans of the division involved.

\section{COMPANY HISTORY}

Midwest Education was started by Henry and Mary Dalton in 1975. Dr. Henry Dalton was an industrial arts teacher before he got his MBA and went on to get his Ph.D. in Technology Education. Mary was a software 
developer who also taught business seminars. At that time a new wave of emerging technology was beginning to alter the way people learn and communicate. By developing Midwest Education, Inc. the Daltons began work in an exciting new field. They found a vast market for quality tools that educated people on how to use all the new technology. Dr. and Mrs. Dalton are in semi-retirement now and travel extensively, but remain major shareholders in the business. They personally hired the CEO when they went into semi-retirement.

The company started with about fifty employees, but has grown consistently and now has a total of 416 employees within its three major divisions: 158 employees work in the Manufacturing Division, 123 work in the Creative Development Division and 135 work in the Transportation, Service and Maintenance Division. There are also 71 employees working at the headquarters in Kansas City (including the corporate staff).

At the beginning on the 1990s it became apparent that international business was becoming the rule rather than the exception. The company went international in 1994 and now is exporting to three European, two Latin American, and two Pacific Rim countries. The Global Operations Division is located within the headquarters.

\section{HEADQUARTERS}

The corporate headquarters are in Kansas City. The CEO of Midwest Education, Inc. is Judith Lund. Ms Lund was hired by the Daltons in 1994 when they decided to take a less active role in the company while remaining major shareholders. Ms. Lund has an MBA in business management, and was previously the CEO of a small telecommunications company. In her previous position, Ms Lund had successfully steered the company out of financial difficulties by raising stock value. She had initiated a strong advertising campaign and had put the company 'in the black' for the first time in seven years.

The COO of Midwest Education, Inc. is Frank Rose. Frank has been with the company since 1989. Mr. Rose, a cousin of Dr. Dalton, had a successful career with an international business training group in California. His desire to move back to his home town of Kansas City came at a time when the Daltons were looking for a COO. He has worked out well for the company.

The Human Resources Department is also located at the headquarters. The Vice President for Human Resources is Lawrence Wilson. Mr. Wilson has a degree in industrial and organizational psychology and an MBA. He has been with the company for 11 years. He started out as a generalist and was promoted as he showed good judgment with hiring and earned his MBA at the same time.

Within the Human Resources Department there are four sections:

1. Staffing, the head of this section is Patrick Shew.

2. Compensation and benefits section, headed by Michael Martin.

3. Labor management relations section, headed by Keith Lane.

4. Training, career development and performance appraisal section, headed by Cynthia Burns.

There are also human resource specialists in each of the three divisions around the country.

\section{MANUFACTURING DIVISION}

The mission statement for the Manufacturing Division is:

"The aim of the Manufacturing Division of Midwest Education, Inc. is to continually improve the quality and strength of all our products. The superior products for which we have become world renowned will still be manufactured along with new and innovative products and ideas. We will work hard to keep quality high and cost down while supplying customers with the best possible products in the shortest possible time." The Manufacturing Division follows a strategy of quality enhancement. 
The main manufacturing plant is located on the outskirts of Kansas City, not far from the company headquarters. The president of the Manufacturing Division is Max Thorn. Mr. Thorn has been with the company almost since its inception. He was one of the first employees hired by the Daltons. He started writing programs for the company and originally worked alongside the Daltons in interviewing and hiring many other employees.

The head of human resources for the Manufacturing Division is Janine Woods. She has a staff of five generalists who assist her in meeting HRM needs for the Manufacturing Division.

The Manufacturing Division used to be housed in the same building as the headquarters. As the business expanded and more room was needed, the division moved to the suburbs into a large factory site. There are 158 employees in the Manufacturing Division. They are divided into ten teams, each team works at producing and packaging a specific product at a time. There are five supervisors who each supervise two teams: Doris Malone, John Fizer, Sandi Cross, Wendy Atchison, and Ian Carpenter.

The Manufacturing Division usually has a long lead time on orders and can anticipate what will be needed. The factory has flexible work areas that can be re-tooled and rearranged for the changeover from one product to another in less than four hours. The pay in this Division starts at $\$ 6.25 / \mathrm{hr}$ for production workers and has a full benefits package. Most employees seem happy with their work. Max Thorn is generally thought of as a good, easy-going man to work for.

\section{CREATIVE DEVELOPMENT DIVISION}

The mission statement for the Creative Development Division is:

"In the Creative Development Division of Midwest Education, Inc. we will strive to bring our customers the most innovative and cutting edge programs and products in the world. Our team of creative professionals is constantly working to improve, upgrade, and create the most useful products to bring to our customers." This division follows a strategy of innovation.

The Creative Development Division has two locations; a headquarters in California and a branch located in Massachusetts. The president of the Creative Development Division is Serena Tibaldo. Ms. Tibaldo recently joined the company. Previously she was a software developer for a large computer game producer. She has a bachelor's degree in business and a computer programming master's degree, and is doing very well at Midwest.

The head of human resources for the Creative Development Division is Amelia Chi, who is located at the California headquarters. Ms. Chi has a staff of five assistants. The head of the human resource section at the Massachusetts branch is Virginia Fox. Ms Fox has a staff of two assistants.

There are 90 people employed at the California plant and 38 at the Massachusetts location. The California location opened in 1980 and the Massachusetts branch was opened in 1993. In the 1970's and 1980's many computer software programmers moved to the west coast to be located in Silicon Valley. Most people hired by Midwest Education, Inc. transferred from wherever they lived to the California branch, with the company paying all relocation expenses. By 1990 some employees desired to live in the east. The Daltons decided it was time to expand the company and in doing so decided the next branch would be in the Massachusetts area. Most of the long time elected to remain California. The majority of recent hires are in Massachusetts.

\section{TRANSPORTATION, SERVICE AND MAINTENANCE DIVISION}

The mission statement for the Transportation, Service and Maintenance Division is:

"The Transportation, Service, and Maintenance Division is committed to providing the fastest and most cost effective way of safely shipping our product to our customers. No effort will be spared as we streamline and 
improve our fast and friendly service". The Transportation, Service and Maintenance Division follows a strategy of cost-reduction.

The Transportation, Service and Maintenance Division headquarters is located in San Antonio, Texas. There are major branches in Baltimore, Maryland and Phoenix, Arizona. The President of the Transportation, Service and Maintenance Division is Mark Derrick. Mr. Derrick is based in San Antonio. Mr. Derrick has been with Midwest Education, Inc. for 13 years. He personally hires the managers for the other branches in Maryland and Arizona.

The head of human resources for the Transportation, Service and Maintenance Division is Salvador Vasquez. Mr. Vasquez has a staff of five assistants. Mr. Vasquez appoints HR heads to the other branches. Often they are employees from San Antonio that he knows well and trusts.

The Transportation, Service and Maintenance Division was originally based in Kansas City. As the company grew a decision was made to relocate the division to Texas. The other branches are newer, with Maryland opening in 1989 and Arizona in 1996. There are 55 employees in San Antonio, and 40 in each of the other two branches.

\section{SITUATION}

Mr. Dalton has called for a senior management retreat and brought the senior staff to Santa Cruz, California. The purpose of the retreat is to explain why there has been a hiring freeze and why no capital equipment purchases for the last 18 months. These funds were used so that Mr. Dalton could purchase a competing business. This is the first meeting of the department heads for both companies. CEO Judith Lund, COO Frank Rose, and VP of HR Lawrence Wilson helped in the acquisition process. This is the first time that Max Thorn, Serena Tibaldo, and Mark Derrick of Midwest Education have been informed of the acquisition.

Mr. Dalton: I have brought everyone here to share my vision for the next phase of our company's growth. I want to thank the senior staff for the excellent job you have done over the past 18 months. The reason for the budget cuts was to raise enough capital to purchase Education Training Aids (ETA). The founder and CEO, Harold Sminsky, has decided to retire, providing us the opportunity to purchase the company that was our primary competitor for the West Coast and Pacific Rim accounts.

The purpose of this retreat is to outline the merger strategy and update our five-year plan for the company. When we started Midwest Education, the vision was to use the latest technology to produce the most effective learning systems for science, technology and business educators. Going forward, we need to stay abreast of current trends and be a leader in our markets. We can't rely on old processes but we must move toward the opportunities that technology affords. With this said, we all need to keep an open mind as we gain economy of scale when the merger is completed.

Judith Lund: Thanks for the introduction, Mr. Dalton. Let me give you a brief outline of the ETA organization. They have two departments; one is Audio Visual Development and Manufacturing, directed by Robert Guio who is based in Anaheim, California. The other department is Computer Development and Communications, directed by Jenny Lutz in San Jose, California. The AV department has a sound stage and recording studios which I will have directed by Serena Tibaldo. The manufacturing facilities will go to Max Thorn. The computer development functions will be split, with computer development going to Serena Tibaldo and the communication portion reporting to Frank Rose. Lawrence has copies for you showing the new corporate organization charts and outlining the new staffing projections.

Lawrence Wilson: For review, Serena has 90 people in California and 38 in Massachusetts. The AV and sound stage facility was a key reason for purchasing ETA. Midwest Education will now be able to keep all the AV production work in house. We will be moving the equipment and the 17 employees to San Jose. ETA computer 
development staff totals 76, bringing Serena's staff to 221. With this increase in mind, I recommend that Serena add regional managers for both the Massachusetts and California operations.

Judith Lund: Serena, you've been doing a good job with your staff. However, by personally managing the daily tasks of your department, you haven't been able to do what you do best - being an innovator of cutting edge training aids. To help you do this, I'm adding a regional manager to the East Coast and West Coast operations. I'm also recommending Robert Guio for one of your regional managers.

Frank Rose: The California office only has enough space for the AV studio, and as for relocating the California operations to a different building, we just renewed the lease for another five years. There is space available at the Massachusetts office that we can expand into. It's my recommendation that most of Serena's additional staff be relocated to the Massachusetts office.

Mr. Dalton: I agree with expanding our East Coast office -- and with the addition of a regional manager for that office, now is the time to do it.

Serena Tibaldo: For East Coast operations I have just the person in mind to promote to regional manager: I would prefer that Mr. Guio work with me here in California. As for increasing the staff in Massachusetts, it would be cheaper to just hire there as needed instead of relocating the remaining ETA staff. The truth is, I'm uncomfortable with just assuming that ETA's computer development staff will fit with my existing employees. I'd agree to conduct interviews with them to see if they can fill the additional positions in Massachusetts.

Jenny Lutz: I understand that we were acquired, but that doesn't mean the ETA staff is inferior to Midwest Educations! For example, last year ETA got seven contracts that were long-time Midwest customers. I think we should look at the combined client base and sort it by location to determine the staffing levels between the East Coast and West Coast operations. Because ETA has several important East Coast clients, the ETA staff currently handling these vital accounts should be moved to the Massachusetts offices where they can better accommodate our customers.

Frank Rose: I agree on the cost issue for hiring versus relocation of employees. On page three, I've included the moving expenses for the last five years by employees and averaged the cost. If we relocate all the ETA employees to Massachusetts it will cost over a million dollars for relocation. We should look at the East Coast positions as new hires. If they want the job then they can pay for the move themselves.

Lawrence Wilson: All ETA's staff are now Midwest Education employees. Historically, we've paid relocation expenses for employees to move to the California office, and we're paying for the AV staff to move from Anaheim to San Jose. We don't have to pay relocation costs to move staff to Massachusetts, but we will have to pay unemployment expenses for any ETA staff we lay off.

Judith Lund: Those are all good points, but we need projected staffing levels for both offices. Serena, when you can have a firm estimate we'll revisit the selection and relocation issues.

Let's move on to manufacturing. ETA has formed an incredible assembly line. Page eleven covers the production costs -- you can see why ETA has been able to underbid us in the past. It's obvious that ETA's manufacturing strategy is cost reduction.

Frank Rose: ETA currently has a manufacturing staff of 103 producing about the same amount as our 158 . The difference makes it imperative that we transition our manufacturing to ETA's equipment.

Judith Lund: ETA has a continuous feed production line and can change production on the fly. We'll be able to do "just in time" manufacturing for most of our products. 
Jenny Lutz: Our strategy was cost reduction, and to achieve this we automated all the processes by installing robotic arms. These robotic arms load the raw materials at the start of the production line, transfer the jobs between processes, and do the final stacking and palletizing of the products. I also have some of my people looking at the start-up costs for a new production run -- ETA has a break-even point at 1000 units.

Max Thorn: That's a good process for our large production lines, but it is not feasible for our specialty products.

Mr. Dalton: ETA's manufacturing equipment is crucial to our growth. We'll be replacing most of the existing manufacturing equipment with ETA's.

Judith Lund: Yes, the equipment will be moved to the Kansas plant.

Lawrence Wilson: How many of the 261 employees in manufacturing will need to be let go once the transition of equipment is completed? The skill sets needed will also change. From a training standpoint, it would be more cost effective and efficient to keep ETA production and quality assurance engineers. Many of Midwest Education's manufacturing employee functions will be replaced by the robotic arms.

Max Thorn: For starters, to get ETA's production to our quality standards, the output will probably drop 5\% to $10 \%$. Still, according to these figures we'll only need about 200 employees to meet our combined production commitments.

Jenny Lutz: ETA is the pioneer of this automated assembly line process. Retention of all ETA's staff will be essential to the relocation of the equipment, and their experience will be crucial to keep operations at minimal costs.

Max Thorn: I admire the success you have achieved with ETA, but cost reduction is not Midwest Education's manufacturing strategy. I agree that ETA's staff will be indispensable in the relocation of the manufacturing equipment, but with about a month or two of training my staff could take the load from there. We've never laid off any employees and I'm not going to start now. Reviewing the current job descriptions at ETA, I would agree to keep twelve of the ETA production design staff. The remaining cuts can come out of ETA's staff.

Jenny Lutz: Let's identify the key skills and match them to the existing staff. The remaining positions can be filled by re-interviewing. This would allow Midwest to cut staff with outdated skills and their deadwood performers.

Frank Rose: Jenny has a good point. If we cut the older staff then it'll reduce our medical expenses, delay retirement payouts, and reduce the payroll. ETA's average pay for manufacturing employees is $8 \%$ less than ours.

Max Thorn: Wait a minute! We can't just cut people because they're older -- we'd be in violation of equal opportunity laws. If we're to maintain a quality strategy, we must be equitable and supportive of our long-term employees. We've got be the leader in fostering commitment by demonstrating that we're committed to our employees.

Lawrence Wilson: Either way, we'll have to pay for unemployment, but we could do this without laying off any employees. What if we were to keep the entire staff and reduce the average hours to 30 hours a week? We keep the hiring freeze in place, and then through attrition and product demand growth, we'll be able to increase the average work week back to 40 hours. This will only take about three to four years.

Max Thorn: What you're suggesting is a $25 \%$ pay cut across the board. If we do that the staff will quit in droves! That's not a quality approach. The crews will be more concerned in getting another part-time job to support their families than maintaining quality of our products.

Mark Derrick: OK, how about this, move the equipment to Mexico because the cost for moving is the same. My brother-in-law's company just moved their plant to Monterrey, Mexico, and cut their manufacturing payroll by $60 \%$. 
Then we use Jenny's approach to identify the key skills, cut the rest, and re-staff in Mexico. Even if we keep the headcount at 261 we would still get a cut in payroll expenses.

Serena Tibaldo: That's a great idea! Relocating to Mexico and re-staffing there has several advantages. Animosity between merged employees would be reduced, much of the automated equipment will be networked together, and we could use the internet with VPN to monitor and update the manufacturing processes. This would help us in developing our Latin markets.

Max Thorn: That's not a very good idea. We have no experience in manufacturing in Mexico nor do I think that any of my managers speak Spanish or would be willing to relocate to Mexico. Let's take that off the table right now.

Judith Lund: I know that we all develop a bond with staff we work around and want to protect those people in our departments, but keep in mind that profitable growth of the company is our first concern. This includes letting go of staff that can't change with the needs of our business. Emotions are high, so let's go to lunch, and when we get back be prepared to discuss the options you've recommended.

\section{Questions}

$1 \quad$ Can Midwest education be selective in who it offers relocation benefits to?

2 Are the employees of ETA who merged with the creative development division guaranteed positions at Midwest Education, or should they be treated as a pool of applicants?

3 Which of the three approaches should Midwest education use to select which manufacturing employees to keep? Is there a better method?

$4 \quad$ Which de-cruitment method is best for a "quality" strategy?

\section{AUTHOR INFORMATION}

Dr. Art Fischer is a University Professor in the Department of Management and Marketing at Pittsburg State University. He is a FELLOW with the American College of Healthcare Executives, and is a retired healthcare executive.

Tom Rush is a student at Pittsburg State University. He has worked in the private sector in the areas of information technology and communications for the past 25 years, and is a member of Phi Theta Kappa and Tau Sigma.

\section{NOTES}


NOTES 